\title{
Tradisi Babanyo di Kabupaten Bandung Barat untuk Bahan Pembelajaran di SMA
}

\author{
Fachmi Fachrurrofi \\ MAN Kota Cimahi \\ fachmifachrurrofi21@gmail.com
}

\begin{abstract}
Sejarah Artikel: Diterima (20 Oktober 2018); Diperbaiki (07 November 2018); Disetujui (20 Januari 2019); Pusblished (30 April 2019).

Bagaimana mengutip artikel ini (dalam gaya APA): Fachrurrofi, F. (2019). Tradisi Babanyo di Kabupaten Bandung Barat untuk bahan pembelajaran di SMA. Lokabasa, 10(1), 1-11. doi: 10.17509/jlb.v10i1.16931
\end{abstract}

Abstrak: Tujuan dari penelitian ini yaitu untuk mendeskripsikan: 1) tradisi babanyo di Kacamatan Cihampelas Kabupatén Bandung Barat; 2) unsur semiotik yang terdapat dalam tradisi babanyo; serta 3) bahan ajar membaca artikel tradisi babanyo di SMA kelas XII. Metode yang digunakan dalam penelitian ini yakni metode deskriptif dengan menggunakan teknik observasi, wawancara, dan dokumentasi. Sumber data dalam penelitian ini adalah paraji (dukun beranak) serta ibu-ibu yang tahu dan pernah melaksanakan tradisi babanyo. Hasil dari penelitian ini yaitu: 1) deskripsi mengenai tradisi babanyo yang mencakup: keadaan, tujuan, properti dan makanan yang disediakan, langkah-langkah dalam pelaksanaan tradisi babanyo, dsb; 2) unsur-unsur semiotik yang terdapat dalam tradisi babanyo berjumlah 30, yang terdiri dari ikon yang terdiri atas 13 unsur, indeks yang berjumlah 3, serta simbol yang berjumlah 14. Aspék yang dominan dalam tradisi ini adalah simbol, hal ini dikarenakan tanda yang termasuk kedalam simbol mempunyai jumlah paling banyak, dibandingkan dengan ikon dan indeks. Tanda-tanda tersebut saling berkaitan serta sudah menjadi satu kesatuan yang membentuk suatu tradisi; dan 3) hasil dari penelitian ini bisa dijadikan alternatif bahan pembelajaran membaca artikel di SMA kelas XII.

Kata Kunci: Semiotik; tradisi babanyo; bahan pembelajaran

\section{Babanyo Tradition In Cihampelas Kabupaten Bandung Barat For Article Reading Learning Materials In 12th Grade Of Senior High School}

Abstract: The purpose of this study is to describe: 1) babanyo tradition in Cihampelas Kabupaten Bandung Barat; 2) semiotic elements contained in the babanyo tradition; and 3) teaching materials to read the articles of babanyo tradition for 12th grade of senior high school. The method used in this study was descriptive method by employing observation, interview, and documentation as its techniques. The data sources in this study were paraji (midwife) and mothers who knew and had carried out babanyo tradition. The results of this study are: 1) a description of the babanyo tradition which includes: conditions, objectives, property and food provided, and the steps in implementing the babanyo tradition, etc .; 2) the semiotic elements contained in babanyo tradition are amounted to 30, which are the icons consisting of 13 elements, 3 indexes, and 14 symbols. The dominant aspect in this tradition is the symbol, this is due to the signs that included to the symbols have the highest total numbers, compared to the icons and the indexes. The signs are interrelated and have become a unit that forms a tradition; and 3) the results of this study can be used as an alternative learning material for articles reading in 12th grade of senior high school.

Keywords: Semiotic; babanyo tradition; learning material 


\section{PENDAHULUAN}

Saat mengalami suatu proses kehidupan yang dianggap penting, biasanya proses tersebut selalu dibarengi dengan dilaksanakannya suatu ritual atau upacara adat. Dalam kamus antropologi dijelaskan bahwa upacara (ritual, ceremony) diartikan sebagai sistem aktivitas atau rangkaian tindakan yang ditata oleh adat atau hukum yang berlaku dan berhubungan dengan berbagai macam peristiwa tetap yang biasanya terjadi pada masyarakat yang bersangkutan" (Pudentia dalam Sugiana, dkk., 2014 hlm. 106). Upacara-upacara adat tersebut sudah menjadi suatu kebiasaan yang diwariskan secara turun- temurun melewati proses belajar, hal ini disebut sebagai suatu tradisi.

Rosari (2017, hlm. 292-293) menjelaskan bahwa yang dimaksud dengan tradisi adalah suatu hal yang telah dilakukan sudah sejak lama, dan sudah menjadi bagian dari kehidupan suatu kelompok masyarakat yang menempati suatu negara yang mempunyai kebudayaan, waktu, atau agama yang sama, dan yang paling penting dalam suatu tradisi yaitu adanya informasi yang diteruskan dari satu generasi ke generasi seterusnya, baik itu secara tertulis maupun secara lisan, sebab tanpa adanya hal tersebut, suatu tradisi akan punah.

Di Kecamatan Cihampelas Kabupatén Bandung Barat, ada suatu tradisi yang dilaksanakan pasca melahirkan, yaitu ketika umur bayi baru menginjak 35-40 hari yang disebut tradisi babanyo.

Tradisi babanyo merupakan suatu tradisi yang hampir serupa dengan tradisi pahinum yang dilaksanakan oleh masyarakat Sunda di daerah lainnya, atau dengan tradisi empat puluh harian bayi, seperti tradisi selapanan yang dilaksanakan di Jawa, tradisi turun mandi di Minangkabau, atau marhabaan yang biasa dilaksankan oleh masyarakat yang beragama Islam. Meskipun waktu pelaksanaannya serupa, yakni antara hari ke 35-40 pasca melahirkan, tetapi tradisi- tradisi tersebut memiliki ciri khasnya masing-masing yang tidak dilaksanakan pada tradisi lainnya.

Sedangkan dalam Ensiklopedia Sunda (Rosidi, 2000, hlm.15-16) adat yang dilaksanakan pada hari ke 40 setelah melahirkan paraji mengurut untuk terakhir kalinya. Pekerjaan yang terakhir ini disebut ngurut ngarérékép (yang sebelumnya telah dilaksanakan mengurut pada hari ketiga setelah melahirkan yang disebut ngurut ngirabkeun, lewat tempo tujuh hari setelah itu ngurut ngirabkeun, paraji mengurut lagi. Mengurut yang kedua ini disebut ngurut netepkeun. Setelah itu, selang seminggu diurut netepkeun lagi sampai ngurut ngarérékép). Setelah 40 hari sejak saat melahirkan, paraji beranggapan bahwa pekerjaannya telah selesai, sehingga merasa sudah saatnya menyerahkan urusan bersalin kepada suaminya. Upacara timbang terima dengan disertai ucapan terima kasih dari suami itu disebut sibanyo. Selain dari melaksanakan sibanyo, di hari ke 40 pun dilaksanakan tradisi mahinum, yaitu membuat pahinum/makanan yang dibuat dari umbut kelapa dan kacangkacangan untuk selamatan orang yang baru melahirkan.

Selain dari kurangnya rasa bangga masyarakat terhadap tradisi warisan nenek moyang dan pola pikir yang semakin modern, faktor pelaku aktif/active bearer (paraji) dalam tradisi babanyo pun saat ini semakin sedikit, hal ini disebabkan karena banyak yang sudah meninggal dunia dan tidak ada yang meneruskannya.

Agar tradisi ini dapat dikenal kembali, serta menjadi salah satu cara untuk menumbuhkan rasa bangga dan rasa ingin melestarikan tradisi babanyo kepada generasi muda saat ini, peneliti merasa perlu menganalisis tradisi ini dengan menggunakan kajian semiotik.

Dalam arti sederhana, semiotik adalah 'ilmu tentang tanda'. Tanda yaitu 'hal yang mewakili hal lainnya'. Jadi, semiotik dapat diartikan sebagai 'ilmu yang meneliti segala hal dalam posisinya sebagai 
wakil dari hal yang lainnya'. Semiotik diartikan sebagai ilmu mengenai tanda, sebab semiotik merupakan cabang ilmu yang mempelajari tanda, seperti sistem tanda dan proses digunakannya tanda. (Van Zoes dalam Isnendes, 2010, hlm. 95).

Charles Sanders Pierce merupakan salah satu tokoh yang dianggap sebagai salah satu pencetus dan populer di dunia semiotik. Pierce merupakan filsuf aliran pragmatik Amerika kelahiran tahun 1839 yang mendefinisikan semiosis sebagai hubungan antara tanda, objék dan makna (Sobur, 2016, hlm. 16). Peirce dalam Koswara (2013, kc. 136), menyebutkan bahwa suatu tanda disebut sebagai wakil yang mewakili hal lain disebut sebagai objek (acuan, ia juga menyebutnya sebagai designatum, denotatum, dan kini orang menyebutnya dengan istilah referent). Hal yang mewakili hal lain disebut sebagai penanda, sedangkan hal yang diwakilinya disebut petanda (makna) (Isnendes, 2010, hlm. 95).

Selanjutnya, Peirce menjelaskan bahwa tanda merupakan segala hal yang ada di dalam hal lain untuk menjelaskan suatu hal (Koswara, 2013, hlm. 136). Sedangkan Peirce dalam Haryadi (2013, hlm. 114) menjelaskan bahwa unsur tanda merupakan sarana manusia untuk berkomunikasi. Tanda akan memberi makna kepada segala hal yang terdapat di alam semesta. Berdasarkan objeknya, Peirce membagi semiotik menjadi tiga, yaitu ikon, indeks, dan simbol.

Melihat pengertian-pengertian di atas, dapat disimpulkan bahwa semiotik adalah salah satu cabang ilmu yang mempelajari tanda, sistim tanda, beserta segala hal yang berkaitan dengan tanda tersebut.

Penelitian mengenai suatu tradisi dengan menggunakan kajian semiotik terbilang sudah banyak dilakukan. Namun yang membedakan penelitian ini dengan penelitian sebelumnya adalah objek yang ditelitinya, yaitu tradisi babanyo di Kecamatan Cihampelas Kabupaten
Bandung Barat yang sampai saat ini belum pernah diteliti, padahal tradisi ini merupakan salah satu aset budaya Sunda yang harus terus dilestarikan. Salah satu usaha yang dapat dilakukan agar tradisi ini tidak punah dan dapat diketahui oleh generasi muda saat ini dan seterusnya adalah dengan diperkenalkan di dunia pendidikan (sekolah). Apabila melihat kurikulum yang berlaku saat ini, hasil dari penelitian ini dapat dijadikan alternatif bahan pembelajaran membaca artikel di SMA kelas XII. Maka dari itu, penelitian ini diberi judul "Tradisi Babanyo di Kacamatan Cihampelas Kabupatén Bandung Barat pikeun Bahan Pangajaran Maca Artikel di SMA Kelas XII (Ulikan Sémiotik)".

\section{METODE}

Metode yang digunakan dalam penelitian ini adalah metode deskriptif. Dalam penelitian ini metode deskriptif digunakan untuk mendeskripsikan perkembangan, unsur-unsur, pelaksanaan, unsur semiotik yang terdapat dalam tradisi babanyo, serta penerapan hasil penelitian untuk bahan pembelajaran membaca artikel di SMA Kelas XII.

Patisipan atau sumber data yaitu subjek data yang diteliti. Sumber data yang digunakan untuk memperoleh data mengenai tradisi babanyo beserta segala hal yang berkaitan dengan tradisi ini adalah data dari Ema Rohaéti yang berusia 70 tahun dan Ema Ratmanah yang berusia 55 taun selaku paraji yang memimpin tradisi babanyo. Selain itu, ada juga sumber data yang digunakan untuk membandingkan tradisi babanyo yang dilaksankan zaman dahulu dan tradisi babanyo yang dilaksanakan saat ini, yaitu data dari Ibu Asiyah (57 tahun) yang pernah melaksanakan tradisi babanyo 40 taun yang lalu, serta data dari Ibu Enur (32 tahun) yang melaksanakan tradisi babanyo sataun yang lalu.

Lokasi yang dijadikan tempat penelitian tradisi babanyo yaitu di 
Kecamatan Cihampelas Kabupaten Bandung Barat. Dalam pelaksanaannya, peneliti mengambil sempel di Desa Pataruman dan Desa Cipatik.

Instrumen penelitian yang digunakan untuk mengumpulkan data yaitu kuisioner, pedoman wawancara, kamera, handphone, dan alat tulis.

Teknik mengumpulkan data yang digunakan dalam penelitian ini adalah teknik observasi, wawancara dan dokumentasi.

\section{HASIL DAN PEMBAHASAN Tradisi Babanyo}

Menurut Danadibrata (2009, hlm. 64) dan Satjadibrata (2005, hlm. 59) kata banyo atau babanyo artinya membasuh telapak kaki, contohnya apabila akan masuk mesjid harus babanyo terlebih dahulu; setelah akad nikah, biasanya setelah disawér, pengantin perempuan akan nyibanyoan telapak kaki pengantin laki-laki (setelah acara nincak endog); sedangkan sibanyo yaitu membasuh telapak tangan beserta jari-jarinya yang kotor, contohnya sebelum atau sesudah makan dengan menggunkan tangan.

Tradisi babanyo yaitu salah satu tradsi yang dilaksanakan setelah melahirkan, yaitu ketika usia bayi antara 35-40 hari. Apabila di daerah lain, tradisi babanyo hampir sama dengan tradisi mahinum yang dilaksanakan oleh masyarakat Sunda di daerah lainnya, tradisi selapanan yang dilaksanakan di Jawa, tradisi turun mandi di Minangkabau, atau marhabaan yang biasa dilaksanakan oleh masyarakat yang menganut agama Islam. Meskipun sama-sama dilaksanakan antara hari ke 35-40 setelah melahirkan, tradisitradisi tersebut tentu memiliki ciri khasnya masing-masing.

\section{Perkembangan Tradisi Babanyo di Kecamatan Cihampelas}

Tradisi babanyo yaitu proses akhir paraji merawat orang yang baru melahirkan dan bayinya, merupakan simbol saling memaafkan dari segala dosa antara praji dan orang yang baru melahirkan, hal ini dilakukan karena dikhawatirkan ada halhal yang tidak diridhoi selama paraji merawatnya.

Tradisi babanyo termasuk ke dalam salah satu tradisi yang dilakukan secara sederhana dan tidak melibatkan banyak orang, meskipun termasuk tradisi yang sederhana tapi saat ini orang yang melaksanakannya sudah semakin berkurang.

Berdasarkan hasil wawancara yang dilakukan kepada partisipan, tradisi babanyo sudah ada di Kecamatan Cihampelas Kabupaten Bandung Barat sejak zaman dahulu, meskipun saat ini sudah mengalami perubahan.

Perbedaan tradisi babanyo yang dilaksanakan zaman dahulu dengan tradisi babanyo saat ini bisa terlihat dari syarat dan perlengkapan yang digunakan dalam tradisi ini. Contohnya apabila zaman dahulu menyediakan menyan dan darah ayam sebagai syarat yang harus disediakan, tetapi saat ini syarat tersebut sudah tidak dipakai lagi. Selain itu, ada juga syaratsyarat yang sudah jarang disediakan, seperti boboko yang saat ini sering diganti dengan menggunakan baskom, samping, sambeleun, jarum dan benang jahit, serta uang logam.

\section{Unsur-unsur Tradisi Babanyo}

Berdasarkan hasil observasi pada tanggal 9 Maret 2018 dan 10 Maret 2018, unsur-unsur dalam tradisi babanyo terdiri dari:

1) waktu dan tempat: waktu dilaksanakannnya tradisi babanyo yaitu antara hari 35-40 setelah melahirkan, dan biasanya dilaksanakan pada pagi hari. Sedangkan tempat pelaksanaannya tidak memiliki patokan yang khusus, tapi biasanya dilaksanakan di ruang tengah;

2) pelaku: pelaku dalam tradisi babanyo yaitu paraji, orang yang baru melahirkan, bayi, dan ayah bayi; 
3) perlengkapan dan makanan: perlengkapan dan makanan yang ada dalam tradis babanyo yaitu benang kasur, gunting, boboko/baskom, kunyit, beras, telur ayam kampung, ayam kampung sasapihan, air bunga, makanan ringan, anting, pongpok, pisau untuk menyunat bayi perempuan, betadin, perban, gelas, piring, dan sendok.

\section{Pelaksanaan Tradisi Babanyo}

Tradisi babanyo merupakan salah satu tradisi yang sederhana dan dapat dilaksanakan oleh semua kalangan masyarakat. Sedangkan runtuyan dan tata cara pelaksanaannya beda-beda, hal ini bergantung kepada paraji yang memimpin tradisi ini dan jenis kelamin bayi yang dilahirkan. Meskipun demikian, secara garis besar pelaksanaan tradisi babanyo yaitu ngurut ngarérékép (apabila melahirkan secara normal/tidak disésar), ngageulangan, menggariskan telur ayam kampung di dahi bayi dan ibunya, ngahuripan, dan babanyo. selain dari pada itu, ada juga yang ditambah dengan melaksanakan kegiatan lain yang sesuai dengan permintaan orang yang akan melaksankan tradisi ini, seperti ditambah dengan pelaksanaan nindikan dan nyunatan bayi perempuan.

Dalam pelaksanaan babanyo yang dilaksanakan pada tanggal 09 dan 10 Maret 2018, tidak ditemukan kegiatan ngurut ngarérékép, hal ini disebabkan karena objek yang diteliti melahiran secara sesar. Ngurut ngarérékép yaitu mengurut yang terakhir kalinya dan memiliki tujuan agar merapatkan atau mengembalikan lagi pianakan/rahim ke keadaan seperti sebelum mengandung.

Karena disesar, maka setelah paraji membuka tradisi ini dengan bacaan ayat suci Al-Quran, yaitu surat Al-Fatihah, AlIkhlas enam kali, ayat kursi dua kali, ArRahman ayat 33 lima kali, asihan dua kali, niat adus, syahadat, dan doa keselamatan, sambil mengoles benang kasur dengan kunyit yang nantinya digunakan untuk ngageulangan bayi dan ngahuripan, maka paraji langsung ngageulangan bayi.

Ngageulangan diawali dengan memasangkan benang kasur yang telah diolesi kunyit ke leher bayi yang diibaratkan sebagai kalung emas, lalu ke tangan bayi yang diibaratkan gelang emas, lalu ke kaki bayi yang diibaratkan gelang kaki emas, serta ke pinggang bayi yang diibaratkan sabuk emas. Hal ini memiliki makna agar kelak bayi tersebut diberi rezeki yang berlimpah

Kegiatan selanjutnya yaitu menggariskan telur ayam kampung di dahi bayi dan ibunya, masing-masing sebanyak tiga kali. telur ayam kampung yang berbentuk bulat dan berwarna putih merupakan simbol agar bayi dan ibunya memiliki pemikiran yang bulat dan putih seperti telur ayam kampung.

Selanjutnya ngahuripan. Dalam kegiatan ngahuripan, ayam yang digunakannya adalah ayam sasapihan/ayam kecil yang sudah lepas dari induknya. Kegiatan ngahuripan dimulai dengan memakaikan benang kasur yang sama dengan yang dipakaikan ke bayi pada saat ngageulangan ke kaki ayam, ketika memasangkan benang ke kaki ayam paraji berkata "Anjeun sing sanggem didamel hurip hirup huripna”. Selanjutnya ayam tersebut diusapkan ke dahi bayi dan ibunya oléh paraji sambil berbicara "sing rido manahna, sing soléh manahna, sing bageur, sing anut ka ibu ka rama. Ieu dihuripan ku Ema. Sing janten hurip hirupna Enéng/Ujang sing mulus rahayu, berkah salamet". Setelah itu ayam diberi makan beras yang disediakan di boboko/baskom sebari paraji berbicara: "Sing tiasa marab mawéh ka ibu ka rama, sing tiasa marab mawéh ka kulawargi, sing tiasa marab mawéh ka tatanggi”. Mendengar apa yang dibaca paraji, pada dasarnya makna dari ngahuripan yaitu mendo'akan bayi agar kelak ia dapat mencari rezeki sendiri, sampai ia bisa 
memberi kepada orang tua dan saudarasaudaranya.

Tahapan kegiatan selanjutnya yaitu babanyo atau membasuh tangan paraji dan orang yang baru melahirkan. Babanyo dilakukan di dalam baskom yang berisi air kembang. Dalam pelaksanaannya, paraji mencuci tangan orang yang baru melahirkan dengan tujuan meminta maaf apabila ada hal-hal yang tidak diridoinya selama dirawat oleh paraji. Lain dari pada itu, orang yang baru melahirkanpun mencuci tangan paraji dengan tujuan mengucapkan terima kasih karena paraji telah merawat dirinya dan bayinya. Babanyo dilaksanakan setelah semua runtuyan kegiatan telah dilaksanakan.

Selain yang disebutkan di atas, ada juga yang ditambah dengan kegiatan lainnya, seperti ditambah dengan kegiatan nindikan, nyunatan, membuang tambang di air yang mengalir apabila pada saat bayi lahir tali ari-arinya melilit di lehernya, atau kegitan-kegiatan lain yang melibatkan jasa paraji. Kegiatan-kegiatan tersebut dilaksanakan sebelum babanyo.

Setelah semua kegiatan selesai dilaksanakan, selanjutnya ditutup dengan do'a penutup yang pada hakikatnya mendokan agar si bayi menjadi anak yang soleh/solehah, panjang umur, dilimpahkan rezeki yang banyak, berbakti kepada orang tuanya, dst.

\section{Unsur Sémiotik dalam Tradisi Babanyo}

Berdasarkan hasil penelitian yang dilakukan pada tanggal 9 dan 10 Maret 2018, dalam tradisi babanyo banyak unsurunsur yang mengandung arti. Arti dari unsur-unsur tersebut dapat dikaji dengan ilmu tanda/semiotik dengan berlandaskan teori semiotik Charles Sanders Pierce. Berdasarkan objeknya, Peirce membagi tanda menjadi tiga, yaitu ikon (icon), indeks (index), jeung simbol (symbol) (Haryadi, 2013, hlm. 114).

Tanda yang ditemukan dalam tradisi babanyo yang dilaksanakan pada tanggal 09 dan 10 Maret 2018 berjumlah 30, yaitu terdiri dari ikon yang jumlahnya 13, indeks yang jumlahnya ada 3, serta simbol yang berjumlah 14. Aspék yang paling dominan dalam tradisi ini adalah simbol, sebab jumlah tanda yang termasuk ke dalam simbol lebih banyak dari pada tanda yang termasuk ke dalam ikon dan indeks. Semua tanda tersebut saling beraitan dan sudah menjadi satu kesatuan yang membentuk suatu tradisi, yaitu tradisi babanyo.

\section{Ikon dalam Tradisi Babanyo}

Ikon adalah suatu benda fisik (dua atau tiga dimensi) yang menyerupai apa yang direpresentasikannya. Representasi ini ditandai dengan kemiripan. (Sobur, 2016, hlm. 158). Sebagai contohnya, gambar mobil adalah ikon dari mobil itu sendiri.

Ikon yang ditemukan dalam tradisi babanyo yang dilaksanakan pada tanggal 09 dan 10 Maret 2018 jumlahnya da tiga belas, yaitu (1) paraji, (2) orang yang baru melahirkan, (3) bayi, (4) ayah bayi, (5) ruang tengah, (6) gunting, (7) baskom, (8) kunyit, (9) pisau kecul untuk menyunat bayi perempuan, (10) betadin, (11) perban, (12) anting, dan (13) pongpok.

Istilah-istilah di atas termasuk ke dalam ikon, karena istilah-istilah tersebut serupa dengan apa yang direpresentasikannya. Contohnya gunting, gunting termasuk ke dalam ikon karena menunjukan tanda dari benda yang digunakan untuk memotong, tanpa memiliki maksud lain.

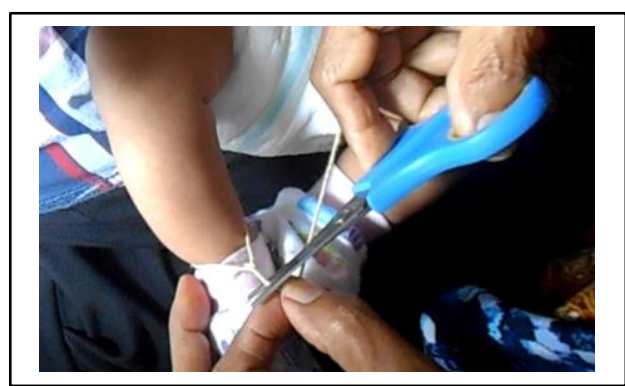

Seperti yang terlihat pada gambar di atas, dalam tradisi babanyo, gunting merupakan alat yang digunakan oleh paraji untuk memotong benang kasur yang telah diolesi kunyit saat ngageulangan. 
sementara gunting tidak memiliki maksud/arti lain.

\section{Indéks dina Tradisi Babanyo}

Indeks yaitu tanda yang bergantung pada denotatum. Indeks merupakan tanda yang menjelaskan adanya hubungan kausal (sebab-akibat). (Peirce dalam Isnendes, 2010, hlm. 96). Contohnya asap yang menandakan adanya api.

Indeks yang terdapat dalam tradisi babanyo yang dilaksanakan pada tanggal 09 dan 10 Maret 2018 jumlahnya ada tiga yaitu (1) asihan, (2) tawasul, dan (3) do'ado'a yang dibaca dari dimulainya tradisi ini sampai do'a penutup.

Asihan, tawasul, dan do'a-do'a termasuk ke dalam indeks karena merupakan tanda yang menjelaskan adanya harapan yang ingin terpenuhi. Contohnya asihan, dibacanya asihan karena adanya keinginan agar bayi yang melaksanakan tradisi ini disayangi oleh banyak orang.

\section{Simbol dina Tradisi Babanyo}

Simbol yaitu benda atau perbuatan yang dikaitkan dengan suatu ide atau gagasan (Hartoko dan Rahmanto dalam Sobur, 2016, hlm. 155). Sedangkan Peirce dalam Isnendes (2010, hlm. 96) menjelaskan bahwa simbol merupakan tanda yang menghubungkan tanda dengan denotatum yang telah ditentukan dan disepakati bersama oleh suatu kelompok masyarakat.

Simbol yang terdapat pada tradisi babanyo yang dilaksanakan pada tanggal 09 dan 10 Maret 2018 jumlahnya ada empat belas, yaitu (1) tradisi babanyo, (2) benang kasur yang diolesi kunyit, (3) ngageulangan, (4) nindikan, (5) nyunatan, (6) ngahuripan, (7) beras, (8) ayam kampung sasapihan, (9) makanan ringan, (10) air bunga, (11) telur ayam kampung, (12) piring, (13) gelas, dan (14) sendok.

Istilah-istilah di atas termasuk ke dalam simbol karena merupakan benda dan perbuatan yang berkaitan dengan suatu gagasan, serta arti dari tanda tersebut bersifat konvensional atau telah disepakati bersama oleh masarakat. Contonya benang kasur yang telah diolesi kunyit merupakan benda yang secara konvensi dianggap sebagai simbol dari perhiasan kalung, gelang, gelang kaki, dan sabuk emas oleh masyarakat Kecamatan Cihampelas Kabupaten Bandung Barat.

Aspék yang dominan dalam tradisi ini adalah simbol, karena jumlah tanda yang termasuk ke dalam simbol lebih banyak dibandingkan dengan jumlah tanda yang termasuk ke dalam ikon dan indeks. Semua tanda tersebut saling berkaitan dan sudah menjadi satu kesatuan sebuah tradisi, yaitu tradisi babanyo.

\section{Bahan Pembelajaran Membaca Artikel Tradisi Babanyo}

Bahan pembelajaran yaitu salah satu komponen yang dapat mendukung tingkat ketercapaian tujuan pembelajaran. Meskipun sifatnya sudah pasti, karena tedapat dalam kurikulum, tapi guru masih dituntut untuk memilih dan menentukan bahan pembelajaran. Guru harus bersikap bijaksana dalam memilih dan menentukan bahan pembelajaran apa yang akan digunakan, tidak bisa seenaknnya dan tidak bisa sesuai keinginna sendiri, tapi harus merujuk kepada beberapa pertimbangan (Haerudin dan Kardana, 2013, hlm. 77). Sedangkan menurut Ruhimat, dkk. (2015, hlm. 152), bahan pembelajaran atau materi ajar pada dasarnya adalah "isi" dari kurikulum, yakni mata pelajaran dengan topik atau sub topik, dan rinciannya. Berdasarkan uraian di atas, dapat disimpulkan bahwa bahan pembelajaran merupakan materi atau isi kurikulum yang dipilih dan ditentukan oleh guru untuk mencapai tujuan pembelajaran.

Pembelajaran membaca merupakan salah satu dari empat pembelajaran bahasa yang diajarkan di setiap jenjang pendidikan, jika melihat kurikulum 2013 revisi 2017 di jenjang SMA, ada materi pembelajaran mengenai artikel, pembelajaran membaca artikel merupakan salah atu KIKD yang harus dicapai dalam 
pembelajaran bahasa dan sastra Sunda yang ada di jenjang SMA, yaitu di kelas XII.

Nasution (dalam Haerudin dan Kardana, 2013, hlm. 77) menjelaskan bahwa bahan pembelajaran harus dipilih berdasarkan kepada lima hal, yaitu:

1) tujuan yang harus dicapai

2) dianggap memiliki nilai-nilai untuk kehidupan manusia

3) dianggap memiliki nilai-nilai yang merupakan warisan dari generasi sebelumnya

4) memiliki manfaat untuk menguasai suatu ilmu

5) sesuai dengan kebutuhan dan minat murid

Melihat kriteria memilih bahan pembelajaran menurut Nasution di atas, hasil dari penelitian ini sesuai dengan kritéria memilih bahan pembelajaran, karena memiliki tujuan yang sesuai dengan KIKD yang tercantum dalam Kurikulum 2013 revisi 2017 yakni untuk menganalisis isi, struktur dan aspek kebahasaan teks artikel berbahasa Sunda (Disdik, 2017, hlm. 40), dalam hal ini artikel yang digunakan adalah artikel tradisi babanyo; dianggap memiliki nilai-nilai untuk kehidupan manusia; nilai-nilai yang terdapat dalam tradisi ini dianggap selaku warisan dari generasi sebelumnya; bahan pembelajaran ini memiliki manfaat untuk menguasai suatu ilmu yaitu mengenai tradisi babanyo; serta bisa menjadi salah satu cara yang digunakan untuk membangun karakter, pemahaman serta menumbuhkan rasa bangga dan minat siswa terhadap tradisi.

Bahan pemebelajaran seperti yang disebutkan, selain memenuhi aspek pokok KIKD, juga dapat menambah pengetahuan siswa tentang khazanah budaya lokal, seperti diistilahkan Suherman (2019, hlm. 348) sebagai kegiatan literasi budaya, khususnya budaya lokal.

Selain dari bahan pembelajaran yang harus memenuhi kriteria memilih bahan pembelajaran, guru dituntut pula untuk bisa menguasai materi mengenai budaya dan tradisi, serta harus bisa menyesuaikan bahan pembelajaran dengan kemampuan siswa agar tujuan pembelajaran bisa tercapai.

\section{SIMPULAN}

Berdasarkan hasil penelitian yang dilaksanakan di Kecamatan Cihampelas Kabupaten Bandung Barat, tradisi babanyo merupakan salah satu upacara yang dilaksanakan setelah melahirkan, yakni pada saat umur bayi antara 35-40 hari, termasuk ke dalam salah satu tradisi yang dilakukan secara sederhana dan tidak melibatkan banyak orang. Tradisi babanyo yaitu proses akhir paraji merawat orang yang baru melahirkan dan bayinya, merupakan simbol dari saling memaafkan dari segala dosa antara paraji dan orang yang baru melahirkan, hal ini dilakukan karena dikhawatirkan ada hal-hal yang tidak diridhoi selama paraji merawatnya. Biasanya tradisi babanyo dilaksanakan pada pagi hari di ruang tengah. Perlengkapan dan makanan yang ada dalam tradis babanyo yaitu benang kasur, gunting, baskom, kunyit, beras, telur ayam kampung, ayam kampung sasapihan, air bunga, makanan ringan, anting dan pongpok, pisau untuk menyunat bayi perempuan, betadin, perban, gelas, piring, dan sendok. Serta dalam pelaksanaannya tradisi ini terdiri dari beberapa kegiatan, seperti membaca do'a dan asihan sembari mengolesi benang kasur dengan kunyit, mengurut ngarérékép (apabila melahirkan secara normal/tidak disésar), ngageulangan, ngahuripan, menggariskan telur ayam kampung di dahi bayi dan ibunya, ngahuripan, dan babanyo. Selain itu, ada juga yang ditambah dengan melaksanakan kegiatan lain yang sesuai dengan permintaan orang yang akan melaksankan tradisi ini, seperti ditambah dengan pelaksanaan nindikan dan nyunatan bayi perempuan, atau kagiatan lain yang melibatkan jasa paraji, hal ini tergantung permintaan orang yang akan melaksanakan tradisi ini. 
Berdasarkan pada hasil penelitian yang dilaksanakan pada tanggal 09 dan 10 Maret 2018 ditemukan ikon yang jumlahnya 13, yaitu (1) paraji, (2) orang yang baru melahirkan, (3) bayi, (4) ayah bayi, (5) ruang tengah, (6) gunting, (7) baskom, (8) kunyit, (9) pisau kecil untuk sunat bayi perempuan, (10) betadin, (11) perban, (12) anting, dan (13) pongpok; indeks yang jumlahnya ada 3 , yaitu (1) asihan, (2) tawasul, dan (3) do'a-do'a yang dibaca dari dimulainya tradisi ini sampai do'a penutup; serta simbol yang berjumlah 14, yaitu 1) tradisi babanyo, (2) benang kasur yang diolesi kunyit, (3) ngageulangan, (4) nindikan, (5) nyunatan, (6) ngahuripan, (7) beras, (8) ayam kampung sasapihan, (9) makanan ringan, (10) air bunga, (11) telur ayam kampung, (12) piring, (13) gelas, dan (14) sendok. Aspék yang paling dominan dalam tradisi ini adalah simbol, sebab jumlah tanda yang termasuk ke dalam simbol lebih banyak dari pada tanda yang termasuk ke dalam ikon dan indeks. Semua tanda tersebut saling berkaitan dan sudah menjadi satu kesatuan yang membentuk suatu tradisi, yaitu tradisi babanyo.

Berkaitan dengan pembelajaran, hasil hasil dari penelitian ini memenuhi kritéria memilih bahan pembelajaran menurut Nasution. Selain dari pada itu, guru dituntut harus menguasai materi mengenai budaya dan tradisi, serta harus bisa menyesuaikan bahan pembelajaran dengan kamampuann siswa agar tujuan pembelajaran dapat tercapai.

\section{UCAPAN TERIMA KASIH}

Alhamdulillahirobbil'alamin, ucapan terima kasih yang penuh dengan rasa syukur kepada Alloh SWT yang telah memberikan kelancaran kepada penulis sampai terselesaikannya jurnal ini serta kepada semua pihak yang telah memberikan bantuan dan dukungannya. Semoga jurnal ini bermanfaat bagi yang membacanya.

\section{CATATAN PENULIS}

Penulis menyatakan bahwa tidak ada konflik kepentingan terkait publikasi artikel ini. Penulis mengkonfirmasi bahwa data dan artikel ini bebas plagiarisme.

\section{PUSTAKA RUJUKAN}

Danadibrata, R.A. (2009). Kamus Basa Sunda. Bandung. Kiblat Buku Utama.

Dinas Pendidikan Provinsi Jawa Barat. (2017). Kurikulum Tingkat Daerah Muatan Lokal Mata Pelajaran Bahasa dan Sastra Sunda Berbasis Kurikulum 2013 Revisi 2017 Jenjang SMA/SMK/MA/MAK. (.pdf)

Haerudin, D. \& Kosim K. (2013). Panganteur Talaah Buku Ajar. Bandung. Jurusan Pendidikan Bahasa Daerah FPBS UPI.

Haryadi, F. (2013). "Nilai Kearifan Lokal dalam Upacara Adat Ritus Tiwu Panganten di Kecamatan Babakan Kabupaten Cirebon (Analisis Struktural-Sémiotik)". Lokabasa. 4, (2), 112-121. Tersedia di: http://ejournal.upi.edu/index.php/lok abasa/artikel/view/3133

Isnendes, R. (2010). Teori Sastra. Bandung. Jurusan Pendidikan Bahasa Daerah FPBS UPI.

Koswara, D. (2013). Racikan Sastra. Bandung. Jurusan Pendidikan Bahasa Daerah FPBS UPI.

Rosari, R.W. (2017). Kamus Seni Budaya. Surakarta: Aksara Sinergi Media.

Rosidi, A. (2000). Ensiklopedia Sunda: Alam, Manusia, dan Budaya, Termasuk Budaya Cirebon dan Betawi. Jakarta. Dunia Pustaka Jaya.

Ruhimat, dkk. (2015). Kurikulum dan Pembelajaran. Jakarta. Rajagrafindo Persada. 
Satjadibrata, R. (2005). Kamus Basa Sunda. Bandung: Kiblat Buku Utama.

Suherman, A. \& Nugraha, H.S. (2019). Culture and Citizenship Literacy in Sundanese Children's Literature. Dalam A.G. Abdullah \& A.A. Danuwijaya (Peny.). Proceeding Second Conference on Language, Literature, Education, and Culture (ICOLLITE) (hlm, 346-348). Paris: Atlantis Press.

Sobur, A. (2016). Sémiotik Komunikasi. Bandung: Remaja Rosdakarya Offset.

Sugiana, U., dkk. (2014). Tradisi Ngayun di Kacamatan Rawamerta Kabupaten Karawang (Kajian StrukturalSémiotik). Lokabasa. 5, (1), 104-110. Tersedia di: http://ejournal.upi.edu/index.php/lok abasa/artikel/view/3166 